\title{
A SMA HIGH PERFORMANCE ACTUATOR FOR ROBOT HANDS
}

\author{
D. REYNAERTS and H.van BRUSSEL \\ Katholieke Universiteit Leuven, Division of Production technology, Machine design and Automation, \\ Celestijnenlaan 300 B, B-3001 Heverlee, Belgium
}

\begin{abstract}
This paper proposes a prototype of a high performance robotic actuator, based on shape memory alloys. The actuator prototype was designed for generating a torque of $75 \mathrm{Nmm}$. It consists of a wire with rectangular section which is driving a pulley system. A bias spring is used to preload the system. This design is to be used within the links of a human-sized multi-fingered robot hand. Therefore a highly miniaturised actuator had to be built. Resistive heating and oil cooling are used to obtain the necessary transformations. Due to the low electrical resistance of the SMA, a specially designed power amplifier had to be developed. A real time position controller for this device is proposed. It is taking into account the hysteresis behaviour of the SMA material. Finally, the first experimental results for this prototype are presented.
\end{abstract}

\section{INTRODUCTION}

When looking at the existing industrial or medical applications for shape memory alloy (SMA) materials, one can state that they are almost exclusively used for on/off applications like cooling circuit valves, fire detection, clamping devices and many others. Recently, research efforts were directed towards some more continuously controllable actuators.

Most studies related to SMA motors or advanced applications point out that SMA actuation is feasible, but is still far from an actuator with reasonable accuracy or velocity. Chaudhuri and Fredericksen (1) proposed some designs of SMA muscles for a robot hand. Hitachi (2) demonstrated the feasibility of a robot-hand actuated by SMA's, without providing a really fundamental study of control and cooling problems. Hirosi (3) presented a theoretical model for the transformation of a SMA. The control problem was partially solved by Kuribayashi (4)(5)(6). He got around the hysteresis problem by restricting displacements to a range of a few tenths of a millimetre and could thus simplify the problem to a linear one. The response of the system could be improved by mounting a small temperature sensor on the SMA elements. Also Dario and Bergamasco (7)(8) developed a SMA based actuator provided with a water cooling circuit. They introduced some limit curves for maximum tension and elongation as a first rough design rule when using SMA materials. Rogers (9) proved it possible to control the dynamic behaviour of a structure utilizing embedded SMA actuator fibres. Recently, feedback of the measured electrical resistance $(10)(11)(12)$ was introduced to obtain a direct stiffness and force control of the actuator, despite that some other authors (13) state that there is no direct relationship between the resistance and the transformation strain.

Summarizing, the two main problems to solve are in the first place, controlling the hysteresis behaviour, and secondly, the development of an efficient heating/cooling method. After this, one can start with pointing out a general design methodology for SMA actuators, which has to be checked by building some prototypes.

\section{MECHANICAL DESIGN OF A ROBOTIC ACTUATOR BASED ON SMA}

\section{a. Material selection}

When starting this research, two groups of shape memory alloys were commercially available : Copper based alloys (CuZnAl and CuAlNi) and NiTi alloys (also called Nitinol). NiTi SMA's are 50 to 100 times more expensive 
than copper based alloys and they are more difficult to machine. Consequently, in most on/off applications like clamps, fire detectors ...copper based alloys are used. Some other disadvantages of NiTi are :

- Lower transformation temperatures. As will be explained further, this aspect influences the actuator bandwidth.

- A considerable hysteresis to cope with when designing a control method.

In spite of this are there several reasons why NiTi was used in our robotic actuator :

- NiTi has a considerably larger resistivity (about 10 times higher) so that smaller currents are to be used in case of resistive heating.

- NiTi has a higher work density (delivered work per volume unit) and has a higher mechanical strength.

- NiTi alloys have, generally spoken, better fatigue properties.

- NiTi has a corrosion resistance comparable to stainiess steel.

Before starting the design of the actuator, several test set-ups were built (16) to study the material behaviour.

\section{b. Shape of the active element}

Cold machining of NiTi is extremely difficult. Therefore the material is mainly available in hot formed (e.g. extrusion wires) and simple cold-formed (e.g. plates) shapes. Electro-discharge machining (EDM) could bring a solution, but when starting from an ingot, a two way shape memory effect is difficult to obtain because this way of processing does not induce any dislocations in the material.

A lot of existing designs are based on SMA springs or very fine wires. When designing an actuator for a humansized multi-fingered robot hand, the most stringent design parameter appears to be the required torque/volume ratio. Main specifications for the actuator are :

- Maximum torque : $\pm 100 \mathrm{Nmm}$.

- Maximum rotation : 90 degrees.

- Volume : $\pm 15 \mathrm{~cm}^{3}$.

Several alternatives were studied :

- The main advantage of a spring is that it generates a large macroscopic displacement out of a relatively small microscopic strain. However, the stress distribution over the cross section of the spring is not constant. This implies that a greater material volume is needed for generating the same force. This has a negative effect on the efficiency and the bandwidth of the spring based actuator. A solution could be the use of a thin-walled cylinder, used as a torsional spring, but this design is not capable of generating enough torque.

- Similar remarks can be made for designs based on flexural deformation of the SMA element.

- Using wires as an active element has the great advantage of optimal use of the material. To generate a sufficient displacement there are two alternatives : using a serial system consisting of a long wire to generate the desired displacement and force or using a parallel system of multiple wires (to generate a large force and a small displacement) in combination with a lever mechanism. For the parallel solution it is difficult to obtain a homogeneous stress distribution (which means equal transformation temperatures) over the different wires. All wire to environment connections also need to have a sufficient mechanical strength and a low electrical resistance.

Because of this, the serial wire solution was chosen for building a first prototype. To improve heat transmission, a rectangular cross section is used. This is obtained by cold rolling of an extruded circular wire.

\section{c. Cooling of the material}

Because of the use of temperatures below $100^{\circ} \mathrm{C}$, only conductive and convective heat transfer to the environment have to be considered. When the enveloping fluid is not moving, the conductive effect is predominant. Convection is the main effect when the fluid is moving. Heat transfer between an object and ambient is given by :

$$
\mathrm{P}=\text { h.q. } \Delta \mathrm{T} \quad \text { where }
$$

$\mathbf{P}$ is the transmitted power

$\mathbf{h}$ is the heat transfer coefficient

$\mathrm{q}$ is the contact surface area

$\Delta \mathrm{T}$ is the difference in temperature between object and ambient

While the transformation temperature mainly determines $\Delta \mathrm{T}$, it is easy to see that the amount of transmitted power 
can be influenced by changing h or $\mathrm{q}$. By using a rectangular cross section wire, the cooling surface was already maximised (taking into account the difficult machining). The maximal heat transfer coefficient is reached in case of a moving liquid (convection). For cooling purposes one could also use Peltier elements or heat sinks. A good heat transfer between active element and cooling device requires in this case a physical connection which is very difficult to realize due to the elongation/contraction cycle of the active element. Therefore, liquid convective cooling was selected in the first prototype.

\section{d. Heating of the material}

Simultaneously heating and cooling by means of fluids is very complicated and has a negative influence on the total bandwidth of the system. As external heating elements are bulky and not very efficient, only resistive or inductive heating remained as valuable alternatives. Inductive heating induces a non-homogeneous temperature distribution over a cross section, which causes internal stresses. Therefore, resistive heating was finally selected. This would not be possible with copper alloys because of their low resistivity.

\section{e. Mechanical design of the prototype}

Fig. 1 shows a first actuator prototype. It uses a Ni 48 Tis2 wire with rectangular section $(1.75 \mathrm{~mm} \times 0.15 \mathrm{~mm})$. The material was trained for an elongation of $3 \%$. Transformation temperatures for this material are :

$\mathrm{A}_{\mathrm{s}}=58^{\circ} \mathrm{C}$ (start of transformation to austenite) $\quad \mathrm{A}_{\mathrm{f}}=63^{\circ} \mathrm{C}$ (end of transformation to austenite)

$M_{s}=52{ }^{\circ} \mathrm{C}$ (start of transformation to martensite) $\quad M_{f}=38^{\circ} \mathrm{C}$ (end of transformation to martensite)

The total wire length is $360 \mathrm{~mm}$. A pulley system was designed to fit the wire into one phalanx of the robot finger. The pulleys are made of Ertalon 4.6 which is providing electrical insulation combined with good machinability and high temperature stability. A bias spring $(1 \mathrm{~N} / \mathrm{mm})$ is provided to preload the wire. Because both the SMA and the bias spring have an electrical resistance of about $1 \Omega$, the bias spring needed a copper wire by-pass so that only the SMA is heated. The overall dimensions of the actuator are :

length: $40 \mathrm{~mm} \quad$ volume : $18 \mathrm{~cm}^{3}$

width : $30 \mathrm{~mm}$ rated torque : $75 \mathrm{Nmm}$

height : $15 \mathrm{~mm} \quad$ maximum rotation : 90 degrees

weight : $50 \mathrm{gr}$

One end of the wire is connected to the housing. The other end is glued to the final pulley with an epoxy resin. Some experiments proved this is the only reliable fixation. This pulley is transmitting the torque to the output axis which generates the desired rotation. All other pulleys are free-wheeling on ball-bearings. When using a circular form for the final pulley, the torque generated by the bias spring would be a linear function of the rotation (fig. 2). Therefore a cam-shaped pulley is provided so that the bias torque is limited.

An external optical incremental encoder is provided to measure the joint rotation. This bulky device can be eliminated by using built-in Hall-effect sensors.

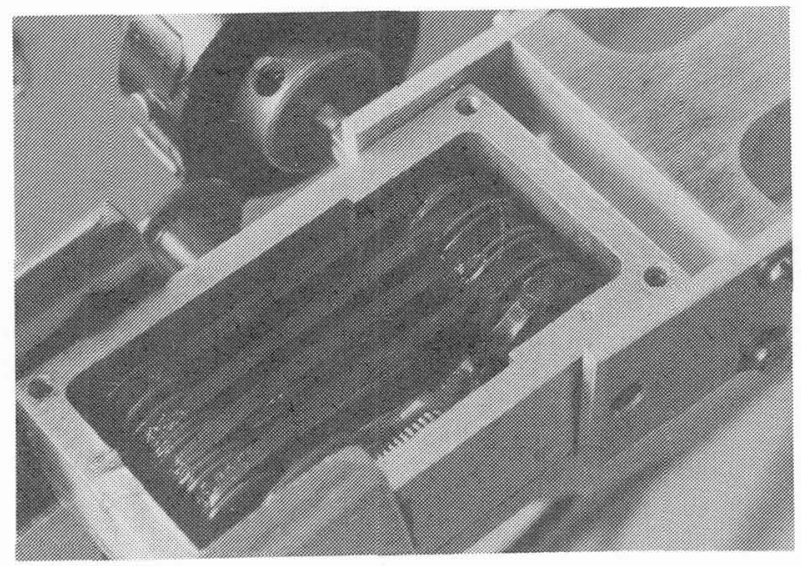

Fig. 1 : Actuator prototype.

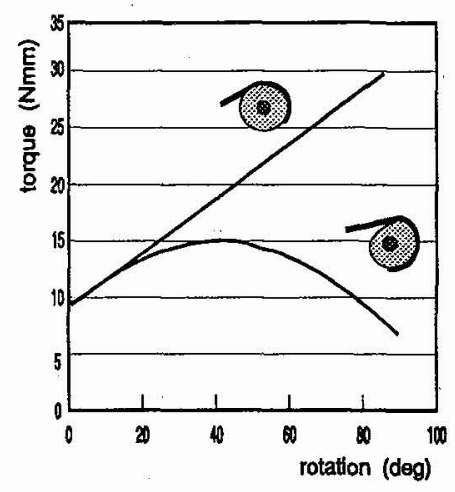

Fig. 2 : Bias torque / Cam shaped pulley. 


\section{f. Driving electronics}

Due to the low resistance of the wire $(1 \Omega)$ the development of the driving amplifier poses some special problems. A SCR-controlled current amplifier with rated power of $15 \mathrm{~W}$ and peak power of $100 \mathrm{~W}$ was built. An integrated multiplier provides a power measurement. As it is very difficult to measure the instantaneous temperature of the SMA, a power measurement is used to calculate the temperature of the material.

\section{MEASURED CHARACTERISTICS}

\section{a. Nonlinear behaviour}

Shape memory alloys show already a nonlinear behaviour by nature. In addition to the thermal hysteresis that shows up when working under isotonic conditions, following factors are also involved :

- Due to the non-constant bias torque, the actuator is not working under isotonic conditions. So stress-induced martensite will influence the transformation temperatures. This factor becomes even more important when working against an external load.

- As a thyristor controlled amplifier is used, the power output is not proportional to the cut-off angle determined by the input signal

When taking all this factors into account, the measured relation between power input and output rotation is given by fig. 3. This curve is obtained under equilibrium conditions at an oil flow of $0.9 \mathrm{ml} / \mathrm{s}$.

\section{b. Dynamic behaviour}

Fig 4,5,6 show the response on a sine input of respectively $0.1,0.8$ and $2.3 \mathrm{~Hz}$. At the higher frequency, the phase shift between input and output signals is about 60 degrees. The main problem for extending the bandwidth of the system is the cooling. Under working conditions, the temperature of the cooling oil reaches $33^{\circ} \mathrm{C}$, while the 10-

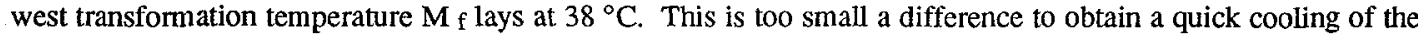
material. So higher transformation temperatures or a colder cooling fluid have to be used. The technical feasibility of these solutions is still to be verified.

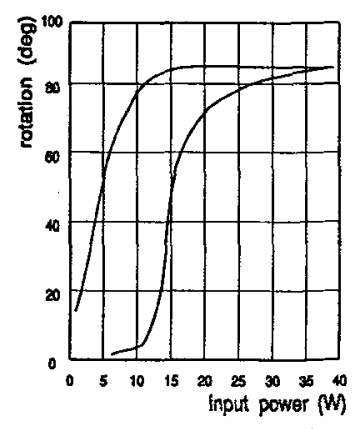

Fig. 3 : Measured hysteresis behaviour.

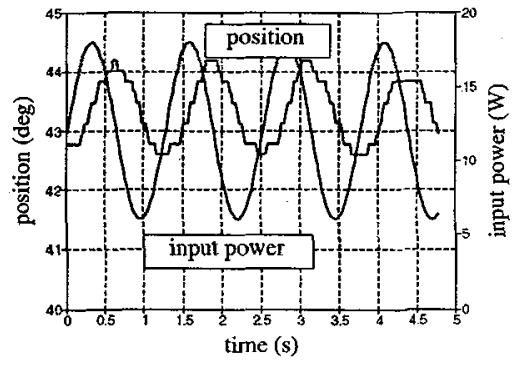

Fig. 5 : Response to sine input $(0.8 \mathrm{~Hz})$.

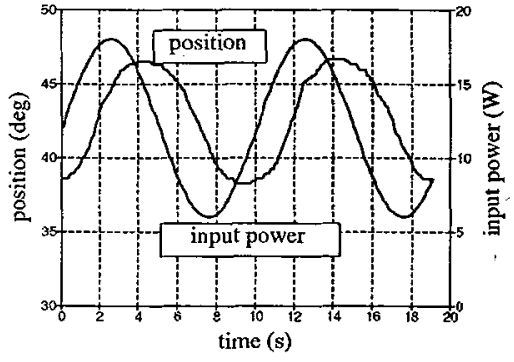

Fig. 4 : Response to sine input $(0.1 \mathrm{~Hz})$.

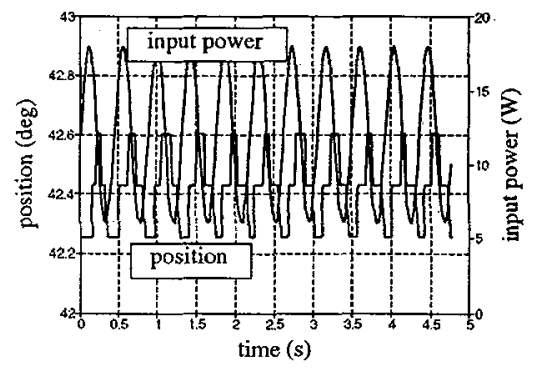

Fig. 6 : Response to sine input $(2.3 \mathrm{~Hz})$. 


\section{c. Energetic efficiency}

To keep the material at a constant temperature, simultaneous heating and cooling of the material is needed. So it is evident that the energetic efficiency of a SMA actuator will be very low. To obtain a high bandwidth, a highly performing cooling method is needed, but this has a very negative influence on the efficiency.

A preliminary study showed already the low energetic efficiency. When using a straight wire of $0.17 \mathrm{~mm}$ and forced air cooling, an efficiency of $0.03 \%$ was obtained. For the discussed actuator with forced oil cooling the calculated efficiency was about $0.008 \%$. This shows that SMA actuation can only be justified when its compactness is really needed.

\section{DESIGN OF A POSITION CONTROL METHOD}

\section{a. Open loop position control}

As discussed in (16), an open loop control of a SMA actuator could be possible by using a simulation model for the $T$,s,e behaviour. Two models were studied (14)(15), but there are still some problems to simulate the behaviour of the NiTi alloy that was used. As also the stress in the material has to be known, some force measurement should be added. However the real force of this method lies in a combined use together with a closed loop position control.

\section{b. Closed loop position control}

A modified PID controller as shown in fig. 7 was developed. It is using the data of fig 3 . to make some estimation of the power needed to keep the actuator in a certain position. To make a accurate estimation without the need of experimental curves, could be a useful application for the above mentioned models. The PID control system is used to compensate for errors in the estimation. A power limitation is provided to prevent burning of the material. Fig. 8 shows the response to a step input. The input power was limited to $80 \mathrm{~W}$. Fig. 9 shows some other positioning results.

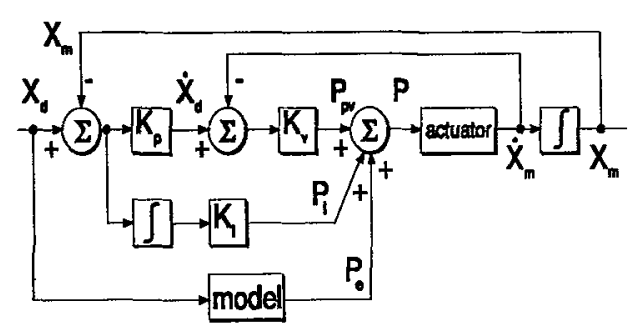

Fig. 7 : Modified PID position controller.

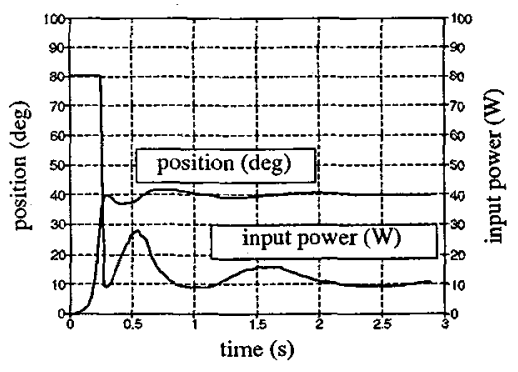

Fig. 8 : Closed loop response to step input.

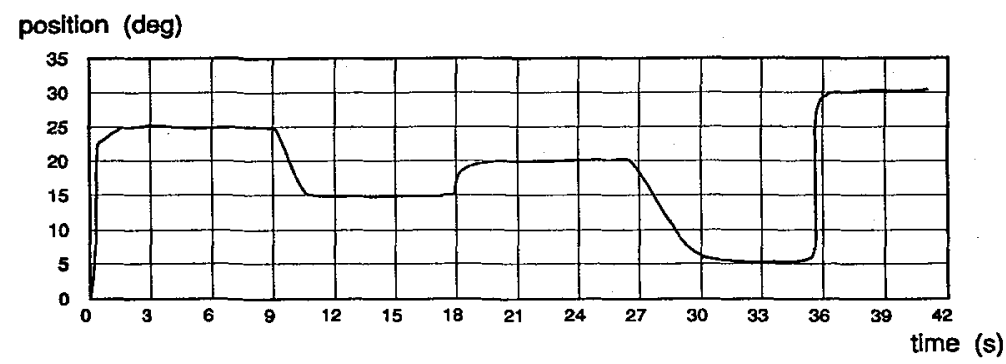

Fig. 9 : Position control. 


\section{CONCLUSION}

A prototype of a high performance robotic actuator is proposed. Starting from the material knowledge and some technological aspects, the most suitable way of heating and cooling is determined. Furthermore, an "optimal" shape for the shape memory element was determined.

The actuator prototype was designed for generating a torque of $75 \mathrm{Nmm}$. It consists of a wire with rectangular section which is driving a pulley system. A bias spring is used to pull the system back. This design is to be used within the links of a human-sized multi-fingered robot hand. Therefore a highly miniaturised actuator had to be built. Resistive heating and oil cooling are used to obtain the necessary transformations. Due to the low electrical resistance of the SMA, a specially designed power amplifier had to be developed. A real time position controller for this device is proposed. The hysteresis behaviour of the SMA material is also taken into acount. Finally, the first experimental results for this prototype were presented.

\section{ACKNOWLEDGEMENT}

The authors wish to thank J.Colruyt and L.Speeleveld for their contribution to this research. This work was supported by IUAP 13, an Inter-University Attraction Pole granted by the Office of the Prime Minister - Science Policy Programming.

\section{REFERENCES}

(1) CHAUDHURI P. FREDERICKSEN D.H., Robothand with shape memory musculature, IBM Technical Disclosure Bulletin Vol. 28 No. 1, June 1985.

(2) NAKANO Y. FUJIE M. HOSADO Y., Hitachi's robothand, Robotics Age, July 1984.

(3) HIROSE S. IKUTA K. UMETANI Y., A new design method of servo-actuators based on the shape memory effect, Theory and Practice of Robots and Manipulators. Proc. of RoManSy '84, 5th CISM IFToMM Symposium, Hermes Publishing, 1985

(4) KURIBAYASHI K., A new actuator of a joint mechanism using NiTi alloy wire, Int. J. Rob. Res. Vol. 4 No. 4, Winter 1986, Massachusetts Institute of Technology.

(5) KURIBAYASHI K., A new compact robot hand using shape memory alloy actuator, Japan-U.S.A. symposium on flexible automation

(6) KURIBAYASHI K., Improvement of the response of a SMA actuator using a temperature sensor, Int. J. Rob. Res, Vol 10, Nr 1, Feb 1991.

(7) BERGAMASCO M., SALSEDO F., DARIO P., A linear SMA motor as direct drive robotic actuator, IEEE Conf. Rob. Aut., 1989

(8) DARIO P., BERGAMASCO M., SALSEDO F., Shape memory alloy micromotors for direct drive actuation of dexterous artificial hands, Sensors \& Actuators, 17, 1989, pp. 115-119.

(9) ROGERS C.A. BARKER D.K., Experimental studies of active strain energy tuning of adaptive composites, 31st AIAA/ASME/ASCE/AHS/ASC Structures Structural Dynamics and Materials Conf., Long Beach CA 1990.

(10) WALKER J.A., A small rotary actuator based on torsionally strained SMA, IEEE Micro robots \& Teleop workshop, 1987.

(11) HONMA D., MIWA Y., Application of SMA to digital control actuator, Bulletin of JSME, Vol 27, Nr. 230, Aug 1984, pp 1737-1742.

(12) IKUTA K., BEARD D.C, HO S., MOIN H., Direct stiffness and force control of a SMA actuator application to miniature clean gripper, ASME Robotics Research 1989, Vol 14, pp 241-246.

(13) LU L., Modelling the transformation hysteresis of shape memory alloys, PhD thesis, K.U.Leuven Dept. MTM, 1990.

(14) LU L., AERNOUDT E., WOLLANTS P., VAN HUMBEECK J,, DELAEY L., Simulation of Transformation Hysteresis, Z. Metallkde. Bd. 81 (1990).

(15) FAVIER D., Contribution à l'étude théorique de l'élastohysteresis à température variable. Application aux proprietés de mémoire de forme, Institut nationale polytechnique de Grenoble, France.

(16) REYNAERTS D., VAN BRUSSEL H., Development of a SMA high performance robotic actuator, Proc. 5th Int Conf on Advanced Robotics ICAR, 1991, pp 61-66. 